\title{
Obesity is the most influential risk factor of cardiopulmonary endurance in older women
}

\author{
Rita Khairani ${ }^{1}$, Donna Adriani ${ }^{2}$, and Patwa Amani ${ }^{3}$
}

\begin{abstract}
\section{BACKGROUND}

Pulmonary function decreases with age. Similarly, physical exercise capacity measured by maximal oxygen uptake, which is one indicator to measure the level of cardiac and pulmonary vascular resistance, decreases by $>1 \%$ per year. This results in many respiratory diseases that occur in older persons, especially in obese older persons. Pulmonary function is a basic component of cardiopulmonary endurance, besides other factors such as age, hemodynamics, metabolism, and lifestyle. The objective of this study was to determine whether body mass index (BMI) and pulmonary function have a significant association with cardiopulmonary endurance in older women.
\end{abstract}

\section{METHODS}

The study used a cross-sectional design involving 66 subjects aged 60 years and older in South Jakarta. Data was collected by measuring body mass index (BMI), pulmonary function (FEV1, FVC, FEV 1 FVC) and maximal oxygen uptake $\left(\mathrm{VO}_{2} \max \right)$ for cardiopulmonary endurance. Data analysis used simple and multiple linear regression tests in SPSS v.25, with $\mathrm{p}<0.05$.

\section{RESULTS}

Of the 66 older persons, $57.6 \%$ was obese. Pulmonary function of subjects showed restriction (33.3\%), obstruction $(6.1 \%)$ and a combination of restriction and obstruction (1.5\%). Furthermore, mean $\mathrm{VO}_{2}$ max was 12.2 $\mathrm{mL} / \mathrm{kg} / \mathrm{min}$. Multiple linear regression analysis showed a significant association of $\mathrm{BMI}$ and $\mathrm{FEV}_{1} / \mathrm{FVC}$ with $\mathrm{VO}_{2} \max (\beta=-0.56 ; 95 \% \mathrm{CI}=-0.81$ -(-) $0.31 ; \mathrm{p}=0.000 ; \beta=0.09 ; 95 \% \mathrm{CI}=0.01-0.18 ; \mathrm{p}=0.028)$. BMI was the most influential risk factor of $\mathrm{VO}_{2} \max (\mathrm{Beta}=-0.46)$.

\section{CONCLUSIONS}

There was a significant association of $\mathrm{BMI}$ and $\mathrm{FEV}_{1} / \mathrm{FVC}$ with $\mathrm{VO}_{2}$ max, $\mathrm{BMI}$ being the most influential risk factor of cardiopulmonary endurance in older women.

Keywords : Pulmonary function, body mass index, maximal oxygen uptake, obesity, elderly women
${ }^{1}$ Department of Internal Medicine, Faculty of Medicine Universitas Trisakti, Jakarta ${ }^{2}$ Department of Physiology, Faculty of Medicine Universitas Trisakti, Jakarta ${ }^{3}$ Department of Physiology, Faculty of Medicine Universitas Trisakti, Jakarta

\section{Correspondence:}

Rita Khairani

Faculty of Medicine

Universitas Trisakti

J1 Kyai Tapa 260 Grogol

Jakarta, Indonesia

Phone: +62 82124004364

Email : rita.khairani@trisakti.ac.id

ORCID ID : 0000-0001-7831-0816

This open access article is distributed under a Creative Commons AttributionNon Commercial-Share Alike 4.0

International License

Date of first submission, August 14, 2021

Date of final revised submission,

December 2, 2021

Date of acceptance, December 6, 2021

Cite this article as: Khairani R, Adriani $\mathrm{D}$, Amani P. Obesity is the most influential risk factor of cardiopulmonary endurance in older women. Univ Med 2021;40:254-62. doi: 10.18051/ UnivMed.2021.v40.254-262. 


\section{INTRODUCTION}

The population of older persons is increasing rapidly in the world, including in Indonesia. Within a span of five decades, the percentage of the older population (aged $>60$ years) in Indonesia has doubled to $9.6 \%$, or around 25 million people from 1971 to 2019 . $^{(1)}$ In old age, the body experience changes in biological and psychological processes due to aging, which results in susceptibility to degenerative diseases, including those related to the respiratory system. In healthy aging, changes in respiration usually do not lead to serious pulmonary problems. ${ }^{(1)}$ The changes in old age related to the respiratory system include changes in lung parenchymal tissue and structural changes of the thoracic cage, pulmonary function abnormalities, air ventilation and diffusion problems, and decreased respiratory muscle strength leading to low exercise capacity, but these will not cause serious problems, such as airway obstruction or pulmonary parenchymal disease, due to the sufficient functioning of pulmonary reserves capacity. ${ }^{(2,3)}$

In addition, older persons may also experience a decrease in lung stretch capacity caused by a decrease in the elasticity or recoil of the lung parenchyma and chest cavity. This condition is associated with a decrease in energy expenditure of the respiratory system. ${ }^{(2)}$ Pulmonary function tests measure lung volume, capacity and rate of flow, and some measurements such as forced expiratory volume in one second $\left(\mathrm{FEV}_{1}\right)$ and forced vital capacity (FVC) which decreases along with increasing age. Meanwhile, pulmonary capacity remains the same. In addition, forced vital capacity may decrease due to an increase in residual volume and decreased diffusion capacity. ${ }^{(2,4)}$

Cardiopulmonary endurance is defined as the ability of the circulatory, respiratory, and muscular systems to efficiently deliver oxygen and nutrients into the cells through the blood vessels during physical activity. Maximal oxygen uptake $\left(\mathrm{VO}_{2} \max \right)$ is one indicator to measure the level of cardiac and pulmonary vascular resistance, which can determine a person's physical exercise ability. ${ }^{(5)}$ Aging is associated with a progressive decrease in physical activity capacity. In addition, maximal oxygen uptake (VO2 max) decreases by $>1 \%$ per year depending on the individual capacity of physical activity. ${ }^{(3,6)}$ Furthermore, the main problem is a decrease in the maximal oxygen uptake rate or VO2 max, caused by an increase in the ratio of dead space to ventilation volume and the differences in oxygen levels between the alveoli and the arteries that occur during physical activity. ${ }^{(7)}$

Pulmonary function is a basic component of cardiopulmonary endurance although several other factors also are of influence, such as age, hemodynamics, metabolism, and lifestyle. Several studies have been conducted to assess the correlation between age and pulmonary function, such as the study conducted by Roman et al. ${ }^{(8)}$ which found that age can cause a reduction in pulmonary function that cannot be overcome by physical exercise. Decreased pulmonary function can cause limitations in ventilation and reduce the capacity for physical activity. A study by Park ${ }^{(9)}$ showed opposite findings, where high-intensity aerobic exercise had a positive effect on pulmonary function in older women.

Low birth weight, ambient air pollution, obesity, and asthma were confirmed as determinants of lung function impairment among never-smokers. ${ }^{(10)}$ Several studies have reported a reduction in lung volume and capacity in obese individuals as compared to the non-obese..$^{(11-13)}$ One cross-sectional study by Liu et al. ${ }^{(14)}$ showed that there was no evidence that body mass index (BMI) is associated with vital capacity in college students. A study of white morbidly obese subjects with normal lung function demonstrated that increasing levels of BMI were significantly associated with decreasing $\mathrm{pO} 2$ and increasing pCO2 even after adjustments for age, gender, and smoking habit (pack-years). This study also found no association between alterations of vital capacity and BMI. ${ }^{(15)}$ 
Another study involving 60 young healthy male subjects in the age group of 18 to 22 years showed a highly significant negative correlation between obesity and $\mathrm{VO} 2 \max (\mathrm{r}=-0.88$ $\mathrm{p}<0.05){ }^{(16)}$ The Epi Health cohort study involving 12.791 women, aged $45-75$ years, showed that in the absence of central obesity, a high BMI is not related to restrictive lung function impairment but rather to higher lung function. ${ }^{(17)}$ Because the results of these previous studies were inconsistent, therefore a new study was deemed necessary to determine which variables were correlated with cardiopulmonary endurance. The present study aimed to assess the characteristics of older persons and to find out whether BMI and pulmonary function are associated with cardiopulmonary endurance in the elderly.

\section{METHODS}

\section{Research design}

This observational analytic study using a cross-sectional design was conducted in Mampang Prapatan District, South Jakarta, from January-May 2018.

\section{Research subjects}

The sample size was determined based on the results of a preliminary study showing that the Pearson correlation coefficient (r) between BMI and VO2 max was 0.49 (data not shown). Using $\mathrm{r}=0.49, \alpha=0.05$ and $\beta=0.1$ plus anticipated dropout rate of $15 \%$, the optimum sample size was 54 . The inclusion criteria were: i). men and women aged 60-76 years; ii) independent; able to walk without assistive devices; iii) and having signed the consent form. The exclusion criteria were: i) having a history of cardiovascular diseases ii) unable to complete the 6-minute walking test. A consecutive non-random sampling method was used to select the research subjects. Written informed consent was obtained from all subjects prior to participation.

\section{Measurements}

Demographic data, including age and gender, were obtained through interviews. Other parameters measured were BMI, blood pressure, pulmonary function, and the 6-minute walking test. Body height was measured using a height measuring device (Microtoise), with an accuracy of $0.1 \mathrm{~cm}$, while body weight was measured using a stamping scale, with an accuracy of $0.1 \mathrm{~kg}$. BMI was calculated as body mass divided by height squared $\left(\mathrm{kg} / \mathrm{m}^{2}\right)$. Based on BMI, the subjects were categorized as underweight (BMI $<18 \mathrm{~kg} / \mathrm{m}^{2}$ ), normal weight (BMI $18.5-22.9 \mathrm{~kg}$ / $\mathrm{m}^{2}$ ), overweight (BMI $23-24.9 \mathrm{~kg} / \mathrm{m}^{2}$ ), obesity I (BMI $25-29.9 \mathrm{~kg} / \mathrm{m}^{2}$ ), and obesity II (BMI $\left.\geq 30 \mathrm{~kg} / \mathrm{m}^{2}\right)$. ${ }^{(18)}$ Furthermore, blood pressure was measured using a calibrated mercury sphygmomanometer. The measurement of blood pressure was conducted with the subject in a sitting position following standard procedures after taking a rest for at least 5 minutes before the test. Blood pressure was measured in millimeters of mercury $(\mathrm{mgHg})$, consisting of systolic blood pressure (SBP) and diastolic blood pressure (DBP). ${ }^{(19)}$

\section{Pulmonary function tests}

Pulmonary function tests including forced expiratory volume in one second $\left(\mathrm{FEV}_{1}\right)$, forced vital capacity (FVC) and the ratio of $F E V_{1}$ to FVC $\left(\mathrm{FEV}_{1} / \mathrm{FVC}\right)$ were performed using a MIR Spirolab spirometer, based on American Thoracic Society criteria. Briefly, the pulmonary function test was conducted with the subject in a standing position following standard procedures and at least three maneuvers were performed, with the largest FVC and the largest $\mathrm{FEV}_{1}$ observed from all of the acceptable values being reported. $\mathrm{FEV}_{1}$ is forced expiratory volume in one second, i.e. the volume of air exhaled in the first second under force after a maximal inhalation, while FVC is forced vital capacity, i.e. the total volume of air that can be exhaled during a maximal forced expiration effort. The $\mathrm{FEV}_{1} / \mathrm{FVC}$ ratio is the percentage of the FVC expired in one second. ${ }^{(20)}$

\section{Cardiopulmonary endurance}

The data on maximal oxygen uptake were collected using a predictive formula by calculating the results of a 6-minute walking test, and utilizing 
the Nury formula for healthy Indonesian adults (Mongoloid). This test is performed on a straight 15 meter long track with markers every 3 meters, 30 centimeters wide to the right and left from the center line. The subject are to go straight forward as close to the center line as possible. When the subject has arrived at both ends, the subject rotates with the three-step method. The Nury formula which consists of five variables is more applicable because it does not require any measurement tools or specific competency. ${ }^{(21)}$

\section{Statistical analysis}

The collected data were analyzed with the Shapiro-Wilk normality test and the results showed that all variables were normally distributed. Simple and multiple linear regression were used to analyze the relationship between several independent variables and cardiopulmonary endurance as the dependent variable using SPSS v. 25 program. Statistical significance was set at $\mathrm{p}<0.05$.

\section{Ethical clearance}

The research was approved by the Faculty of Medicine Research Ethics Committee Universitas Trisakti under No.119/KER/FK/XII/ 2017.

\section{RESULTS}

A total of 66 subjects was recruited during the study. Table 1 shows that the majority of subjects were older women (98.5\%) with mean age of $64.8 \pm 4.1$ years. Based on BMI, it was found that $57.6 \%$ were obese with BMI of $\geq 25$, that around $24.2 \%$ had normal weight and $16.7 \%$ were overweight, and that only $1.5 \%$ were underweight. Blood pressure assessment showed that the majority of subjects had normal blood pressure $(90.9 \%)$.

The average pulmonary function was still above $70 \%$ in $\mathrm{FEV}_{1}, \mathrm{FVC}$, and the ratio of $\mathrm{FEV}_{1} /$ FVC parameters, thus the average subject still had normal pulmonary function. In addition, around $33.3 \%$ had restriction $(\mathrm{FVC}<70 \%$ ) and $6.1 \%$ had
Table 1. Characteristics of the subjects $(n=66)$

\begin{tabular}{|c|c|}
\hline Characteristics & Mean \pm SD \\
\hline Age (years) & $64.8 \pm 4.1$ \\
\hline Body weight (kg) & $59.2 \pm 9.6$ \\
\hline Body height (cm) & $152.2 \pm 6.8$ \\
\hline Body mass index $\left(\mathrm{kg} / \mathrm{m}^{2}\right)$ & $25.5 \pm 3.8$ \\
\hline Systolic blood pressure $(\mathrm{mmHg})$ & $124.8 \pm 16.1$ \\
\hline Diastolic blood pressure (mmHg) & $79.0 \pm 15.3$ \\
\hline $\mathrm{FEV}_{1}^{\mathrm{a} \S}$ & $75.9 \pm 8.8$ \\
\hline $\mathrm{FVC}^{\mathrm{b}} \S$ & $74.7 \pm 10.2$ \\
\hline $\mathrm{FEV}_{1} / \mathrm{FVC}^{\S}$ & $84.5 \pm 9.1$ \\
\hline $\mathrm{VO}_{2} \max (\mathrm{mL} / \mathrm{kg} / \mathrm{min}) \S$ & $12.2 \pm 3.6$ \\
\hline Normal ${ }^{\S}$ & $39(59.1)$ \\
\hline Restriction $(\mathrm{FVC}<70 \%)^{\S}$ & $22(33.3)$ \\
\hline Obstruction $\left(\mathrm{FEV}_{1} / \mathrm{FVC}<70\right)^{\S}$ & $4(6.1)$ \\
\hline $\begin{array}{l}\text { Combination of restriction and } \\
\text { obstruction } \S\end{array}$ & $1(1.5)$ \\
\hline
\end{tabular}

Notes: ${ }^{\S}$ Data are presented as $\mathrm{n}(\%) ;{ }^{\mathrm{a}} \mathrm{FEV}_{1}=$ forced expiratory volume in one second; ${ }^{b} \mathrm{FVC}=$ forced vital capacity

obstruction (FEV1/FVC $<70$ ), and only $1.5 \%$ had a combination of restriction and obstruction. On cardiopulmonary endurance, the obtained $\mathrm{VO} 2$ max was a minimum of $1.3 \mathrm{~mL} / \mathrm{kg} / \mathrm{min}$ and a maximum of $21.1 \mathrm{~mL} / \mathrm{kg} / \mathrm{min}$ with a mean of 12.2 $\mathrm{mL} / \mathrm{kg} / \mathrm{min}$.

In simple regression analysis, BMI, DBP, FEV 1 and FEV1/FVC were significantly associated with $\mathrm{VO} 2 \max (\beta=-0.67 ; 95 \% \mathrm{CI}=-$ $0.92-(-) 0.49 ; p=0.000 ; \beta=0.08 ; 95 \% \mathrm{CI}=0.01-$ $0.11 ; p=0.016 ; \beta=0.06 ; 95 \% \mathrm{CI}=0.01-0.10$; $\mathrm{p}=0.013 ; \beta=0.15 ; 95 \% \mathrm{CI}=0.06-0.25 ; \mathrm{p}=0.02$; respectively), but in multiple linear regression after adjustment for age, only BMI and FEV1/FVC were significantly associated with $\mathrm{VO} 2 \max (\beta=-$ $0.56 ; 95 \% \mathrm{CI}=-0.81-(-) 0.31 ; \mathrm{p}=0.000 ; \beta=0.09$; $95 \% \mathrm{CI}=0.01-0.18 ; \mathrm{p}=0.028$; respectively). BMI was the most influential risk factor of $\mathrm{VO} 2 \mathrm{max}$ (Beta=-0.46)) compared to $\mathrm{FEV}_{1} / \mathrm{FVC}$ (Beta $=0.23)$ (Table 2).

\section{DISCUSSION}

In this study, the majority of subjects were older women with a mean age of 64.8 years. According to data from the Central Bureau of Statistics, the number of older women is one percent higher than that of older men (10.10\%:9.10\%). In addition, the majority $(63.82 \%)$ in the cohort were the younger old (aged 60-69 years). ${ }^{(1)}$ 
Table 2. Factors associated with $\mathrm{VO}_{2}$ max in elderly women using simple and multiple regression analysis $(\mathrm{n}=66)$

\begin{tabular}{|c|c|c|c|c|c|c|c|}
\hline \multirow{2}{*}{ Variables } & \multicolumn{3}{|c|}{ Simple linear regression } & \multicolumn{4}{|c|}{ Multiple linear regression } \\
\hline & $\beta$ & $95 \% \mathrm{CI}$ & p value & $\beta$ & Beta & $95 \% \mathrm{CI}$ & p value \\
\hline Age & -0.58 & $-2.64-1.48$ & 0.577 & & & & \\
\hline BMI & -0.67 & $-0.92--0.49$ & $0.000 *$ & -0.56 & -0.46 & $-0.81--0.31$ & $0.000^{*}$ \\
\hline SBP & 0.04 & $-0.05-0.06$ & 0.884 & & & & \\
\hline DBP & 0.08 & $0.01-0.11$ & $0.016^{*}$ & 0.18 & 0.06 & $-0.42-0.07$ & 0.547 \\
\hline FEV1 & 0.06 & $0.01-0.10$ & $0.013 *$ & 0.03 & 0.17 & $-0.01-0.07$ & 0.100 \\
\hline FVC & 0.01 & $-0.03-0.03$ & 0.978 & & & & \\
\hline FEV1/FVC & 0.15 & $0.06-0,25$ & $0.002 *$ & 0.09 & 0.23 & $0.01-$ & $0.028 *$ \\
\hline
\end{tabular}

Note : Multiple linear regression adjusted for age; B: regression coefficient; Beta: standardized regression coefficient; $\mathrm{CI}$ : confidence interval

Based on BMI, more than half (57.6\%) of the subjects were obese (BMI $\geq 25)$. Physiological functions in older persons will decrease due to the aging process promoting the occurrence of degenerative diseases. Factors affecting the health of older persons include unhealthy eating habits since early in life and lack of exercise. These main factors will affect susceptibility to diseases in old age. ${ }^{(22)}$

Our study showed that obesity is the most influential risk factor of $\mathrm{VO} 2$ max in the elderly and that obesity significantly decreases cardiopulmonary endurance. This finding confirms a previous report showing that BMI was negatively associated with cardiorespiratory fitness among 151 adolescent girls in South Africa. ${ }^{(23)}$ In the obese, excess fat in the abdominal cavity and chest limits the two primary inspiratory movements: contraction of the diaphragm propelling the abdominal contents downwards and forwards, and increased chest diameter by means of rib movement. ${ }^{(24)}$ The results of this study confirm the presence of a restrictive pattern in obese individuals when they demonstrate a decrease in lung volume and capacity.

Furthermore, age, obesity and comorbidity were identified as a significant predictor of functional decline in future. A previous study has reported that BMI could be one of the independent factors for functional limitations and disabilities due to reduced muscle mass and strength (in those with sarcopenic obesity), such as increased joint dysfunction, limited activities, being prone to falls, having chronic pain, resulting in low quality of life. ${ }^{(25)}$ Both obesity and aging are characterized by low-grade systemic inflammatory conditions and endocrine changes. Aging is associated with increased adipose tissue. This is the primary cause of low-grade systemic inflammation signified by cytokine elevation, reduced respiratory capacity and its resultant decrease in body immune status. This is the major cause of chronically elevated levels of pro-inflammatory cytokines and is associated with reduced muscle strength and decreased immune function. ${ }^{(26)}$

This study showed that most of the subjects still had good pulmonary function. About $40.9 \%$ experienced either restriction, obstruction, or a combination of both, as recorded by spirometry. Due to the aging process, pulmonary function gradually decreases, as recorded by either $\mathrm{FEV}_{1}$, FVC, or peak expiratory flow. Pulmonary function will peak at the age of 20-36 years and will begin to decline along with age, namely about $20 \mathrm{~mL} /$ year, starting at the age of 25 years. In addition, it will decrease even more to $38 \mathrm{~mL} /$ year after the age of 65 years. ${ }^{(27)}$

The results of a cohort study, conducted for more than 10 years in subjects having no previous history of pulmonary disease, indicated that the decrease in $\mathrm{FEV}_{1}$ ranged from 17.7 to $46.4 \mathrm{~mL} /$ year with a median of $22.4 \mathrm{ml} /$ year. In addition, in men the decrease is more rapid (median of $43.5 \mathrm{~mL} /$ year) than in women (median of 30.5 $\mathrm{mL} /$ year). ${ }^{(18)}$ Furthermore, results of another study on subjects aged $25-75$ years that examined the various factors affecting pulmonary function 
indicated that pulmonary function significantly decreased along with increase in age. The decline can occur more rapidly in subjects aged over 60 years and remain constant throughout ages 60 90 years. ${ }^{(28,29)}$

Cardiac and pulmonary endurance is defined as the ability of the heart and lungs to supply oxygen throughout the body in the long term. It is measured by VO2 max, the maximal value of oxygen uptake, distribution, and utilization in the body during physical activity. The VO2 max is an indicator to assess health status including the risk of heart disease in older persons. ${ }^{(30)}$ The present study found a mean VO2 max of 12.25 $\mathrm{mL} / \mathrm{kg} / \mathrm{min}$ as measured by the 6-minute walking test. When compared with the mean VO2 max based on age, the VO2 max value obtained was very poor for subjects aged $56-65$ years or $>65$ years. ${ }^{(2)}$

The subjects were mostly older women who have $40 \%$ lower VO2 max than older men due to their lower percentage of muscle tissue and higher percentage of body fat from their total body weight. Furthermore, hemoglobin levels are different between older men and women. Lower hemoglobin levels in older women lead to lower blood transport capacity and less oxygen uptake in women so that their physical activity capacity is lower than that of older men..$^{(9,30)}$

The blood oxygen-carrying capacity declines slightly with age, around $10 \%$ from 30 to 80 years and in females the decline is much lower than in males. ${ }^{(31)}$ It contributes to the decline in VO2 max in old age. Furthermore, if a person does not do regular exercise, the value decreases more drastically. The combination of aging and sedentary lifestyle dramatically affects oxygen delivery and utilization, and influences $\mathrm{VO} 2$ max capacity. Regular exercise improves oxygen extraction by muscle activity and increases $\mathrm{VO} 2$ max. Furthermore, the $30 \%$ increase in $\mathrm{VO} 2$ max found in the elderly is due to an increase in cardiac output $(70 \%)$ and oxygen extraction $(30 \%)$ by skeletal muscles. ${ }^{(6,32)}$

The results of our study indicated that $\mathrm{FEV}_{\mathrm{1}} /$ FVC was significantly associated with $\mathrm{VO} 2$ max. These results are similar to those of the study conducted by Fatemi et al., ${ }^{(33)}$ in which 51 subjects divided into three groups of $\mathrm{VO} 2$ max level (high, medium, and low) suggested a significant difference $(p<0.001)$ in pulmonary function as assessed by measuring the values of $\mathrm{FEV}_{1}, \mathrm{FVC}$ and $\mathrm{FEV}_{1} / \mathrm{FVC}$, where the lower the pulmonary function, the lower the level of VO2 max.

The measurement of pulmonary function can be influenced by several factors, such as height and weight, measurement position, respiratory muscle strength, the condition of the lung, and thoracic cavity expansion. Several factors that can affect vital capacity are age, sex, height, physical exercise, and possibly ethnicity and comorbidities. The spirometry results also depend on the effort and consistency of the subject. ${ }^{(34)}$

Doewes et al. ${ }^{(35)}$ assessed the correlation of pulmonary function, hemoglobin, and heart rate with $\mathrm{VO} 2$ max in athletes of several sports. They showed that the contribution of the respiratory system (tidal volume) to $\mathrm{VO} 2$ max was $12.32 \%$, which was far below that of the cardiovascular system (36.97\%) and the oxygen transport system (49.29\%). The contribution of the respiratory system depends on the type of sport performed. The largest contribution was found in swimming, followed by badminton. Meanwhile, the smallest was found in volleyball.

The insignificant association between other pulmonary function parameters and $\mathrm{VO} 2$ max may also have been caused by obesity because the mean BMI of the subjects was in the obesity category. The results of the multiple regression analysis between BMI and VO2 max indicated a significant negative association, meaning that the higher the BMI, the lower the VO2 max. Body mass index also has its limitations in assessing body composition because it cannot distinguish between body fat and lean mass. Furthermore, it cannot provide the adiposity index, weak distribution, and metabolic risk. In addition, the BMI score can be influenced by age, gender, and ethnicity. ${ }^{(36)}$ 
There are some other factors that affect lung compliance in obesity. The position of the diaphragm in the thoracic cavity is obviously elevated when the individual gains weight. The change will result in a decline in pulmonary function and in the extra work of breathing. Fat accumulation on the chest wall will impede the movement of the thoracic cage by a direct resistance or the abnormal function of the intercostal muscles. Obesity increases the release of inflammatory markers in the lung, with slight effect on airway diameter, is related to the lung volumes not airway obstruction. ${ }^{(12)}$

An increase in age and BMI may cause a decrease in VO2 max. Decreased pulmonary function is associated with decreased respiratory muscle strength and decreased elasticity of pulmonary tissue. Physical exercise will increase $\mathrm{VO} 2$ max due to oxygen consumption and concurrent increase in muscle performance. The ability of muscles to generate aerobic energy optimally will increase the maximal oxygen uptake capacity. ${ }^{(6,35)}$

The beneficial effects of 12 weeks sprint interval training among obese subjects on $\mathrm{VO} 2$ max while concurrently decreasing body fat distribution was found by Bagley et al. ${ }^{(36)}$ After completion of the 12-week exercise, there was an increase in VO2 max of $18.7 \%$ in women and $6.0 \%$ in men. Men and women both improved their VO2 max, but the increases among women were greater than in men. A higher amount of lean body mass was found in men as compared to women, which partially explains the differences between men and women in maximal oxygen capacity. Maintaining physical activities in older persons is an integral part of the healthy aging process and minimizes multi-pathologies. Decreased pulmonary function may cause limitations in physical activity that contribute to low activity tolerance and compliance in healthy aging, especially in older persons who experience gradual lowering of their internal capacity. ${ }^{(8)}$

This study has several imitations. First, BMI takes no account of body fat distribution as an indicator of obesity. Differences in fat distribution may cause changes in lung function. Second, the examination of pulmonary function is also influenced by the effort and consistency of the subjects following the aforementioned procedures with all their limited internal capacities. In addition to the respiratory system that affects VO2 max, other factors, such as the cardiovascular and oxygen transport systems, were not investigated in the study. This study showed that obesity in older persons especially women and decreased pulmonary function may cause limitations in physical activity that contribute to low activity tolerance and compliance in healthy aging, especially in older persons who experience gradual lowering of their internal capacity.

In future, it is recommended that chest, abdominal and hip circumferences or their ratios are used instead of BMI. Other factors that affect cardiopulmonary endurance in older persons should also be investigated.

\section{CONCLUSIONS}

The study demonstrated that increased BMI correlates with decreased cardiopulmonary endurance in the elderly women. It also reinforced the tendency that women in the older population with sarcopenic obesity and decreased pulmonary capacity will be more susceptible to both non-communicable and communicable diseases.

\section{CONFLICT OF INTERESTS}

The author(s) declared no potential conflicts of interest with respect to the research, authorship, and/or publication of this article.

\section{ACKNOWLEDGEMENT}

The authors wish to express their gratitude to the Faculty of Medicine, Universitas Trisakti, for the funding of this study. 


\section{CONTRIBUTORS}

All authors will take public responsibility for the content of the manuscript submitted to Universa Medicina. RK contributed to the concept and design of the study and to data acquisition, analysis, and interpretation. DA and PA contributed to the critical revision of the manuscript. All authors have read and approved the final manuscript.

\section{REFERENCES}

1. Badan Pusat Statistik. Statistik penduduk lanjut usia 2019. Jakarta: Badan Pusat Statistik;2019.

2. Lee D, Artero EG, Sui X, Blair SN. Mortality trends in the general population: the importance of cardiorespiratory fitness. J Psychopharmacol 2010:24(4 suppl):27-35. doi: 10.1177/ 1359786810382057

3. Lee SH, Yim SJ, Kim NC. Aging of the respiratory system. Kosin Med J 2016;31:1 1-18. doi:10.7180/ kmj.2016.31.1.11.

4. Brandenberger C, Muhlfeld C. Mechanisms of pulmonary aging. Cell Tissue Res 2017;367:46980. doi:10.1007/s00441-016-2511-x.

5. Snarr R, Chrysosferidis P, Tolusso DV. Understanding the physiological factors of VO2 max. Personal Training Quarterly 2018;5:16-18.

6. Strasser B, Burtscher M. Survival of the fittest: VO2 max, a key predictor of longevity? Front Biosci 2018;23:1505-16. doi: 10.2741/4657.

7. Hassel E, Stensvold D, Halvorsen T, Wisloff U, Langhammer A, Steinshamn S. Association between pulmonary function and peak oxygen uptake in older persons: the Generation 100 study. Resp Res 2015:16:156-63. doi: 10.1186/s12931-0150317-0.

8. Roman MA, Rossiter HB, Casaburi R. Exercise, ageing and the lung. Eur Respir J 2016;48:147186. doi: 10.1183/13993003.00347-2016.

9. Park J, Han D. Effects of high intensity aerobic exercise on treadmill on maximal-expiratory pulmonary capacity of elderly women. J PhysTher Sci 2017;29:1454-7. doi: 10.1589/jpts.29.1454.

10. Warkentin MT, Lam S, Hung RJ. Determinants of impaired lung function and lung cancer prediction among never-smokers in the UK Biobank cohort. EBioMedicine 2019;47:58-64. doi: 10.b1016/ j.ebiom.2019.08.058.

11. Byberg KK, Mikalsen IB, Eide GE, Forman ML, Júlíusson PB, Oymar K. The associations between weight-related anthropometrics during childhood and lung function in late childhood: a retrospective cohort study. BMC Pulm Med 2018; 18:10. doi: 10.1186/s12890-017-0567-3.

12. Wang S, Sun X, Hsia TC, Lin X, Li M. The effects of body mass index on spirometry tests among adults in Xi'an, China. Medicine (Baltimore) 2017;96:e6596. doi: 10.1097/MD.000000000000 6596.

13. Melo LC, Silva MA, Calles AC. Obesity and lung function: a systematic review. Einstein (Sao Paulo) 2014;12:120-5. doi: 10.1590/s1679$45082014 \mathrm{rw} 2691$.

14. Liu P, Ye Z, Lu H, et al. Association between body mass index (BMI) and vital capacity of college students of Zhuang nationality in China: a cross section study. Oncotarget 2017;8:80923-33. doi: 10.18632/oncotarget.20758.

15. Gabrielsen AM, Lund MB, Kongerud J, Viken KE, Roislien J, Hjelmesaeth J. The relationship between anthropometric measures, blood gases, and lung function in morbidly obese white subjects. Obes Surg 2011;21:485-91. doi:10.1007/ s11695-010-0306-9.

16. Setty P, Padmanabha BV, Doddamani BR. Correlation between obesity and cardio respiratory fitness. Int J Med Sci Public Health 2013;2:298-302. doi:10.5455/ijmsph.2013.2.298-302.

17. Svartengren M, Cai GH, Malinovschi A, et al. The impact of body mass index, central obesity and physical activity on lung function: results of the EpiHealth study. ERJ Open Res 2020;6:002142020. doi: 10.1183/23120541.00214-2020.

18. Ogedegbe G, Pickering T. Principles and techniques of blood pressure measurement. Cardiol Clin2010;28:571-86. doi: 10.1016/j.ccl.2010. 07.006 .

19. Graham BL, Steenbruggen I, Miller MR, et al. Standardization of spirometry 2019 update. An official American Thoracic Society and European Respiratory Society technical statement. Am J Respir Crit Care Med 2019;200:e70-e88. doi: 10.1164/rccm.201908-1590ST.

20. Nusdwinuringtyas N, Laksmi W, Bachtiar A. Healthy adults maximum oxygen uptake prediction from a six minute walking test. Med J Indones 2011;20:195-200. doi: 10.13181/mji.v20i3. 452.

21. Lim JU, Lee JH, Kim JS. Comparison of World Health Organization and Asia-Pacific body mass index classifications in COPD patients. Int J Chron Obstruct Pulmon Dis 2017;12:2465-75. doi: 10.2147/COPD.S141295. eCollection 2017.

22. Pollock RD, Carter S, Velloso C. An investigation into the relationship between age and physiological function in highly active older 
adults. J Physiol 2015;593:657-80. doi: 10.1113/ jphysiol.2014.282863.

23. Bonney E, Ferguson G, Smits-Engelsman B. Relationship between body mass index, cardiorespiratory and musculoskeletal fitness among South African adolescent girls. Int J Environ Res Public Health 2018;15:1087. doi: 10.3390/ijerph15061087.

24. Rabec C, de Lucas Ramos P, Veale D. Respiratory complications of obesity. Arch Bronconeumol 2011;47:252-61. doi:10.1016/j.arbres.2011.01.012.

25. Cheng FW, Gao X, Diane LB, et al. Obesity as a risk factor for developing functional limitation among older adults: a conditional inference tree analysis. Obesity 2017;25:1263-9. doi:10.1002/ oby. 21861.

26. Pusat Data dan Informasi Kementerian Kesehatan. Elderly Health Profile in Indonesia. Buletin Jendela Data Dan Informasi Kesehatan: Jakarta. 2018.

27. Thomas ET, Guppy M, Straus SE, Bell KJL, Glasziou P. Rate of normal lung function decline in ageing adults: a systematic review of prospective cohort studies. BMJ Open 2019;9: e028150. doi:10.1136/bmjopen-2018-028150.

28. Pruthi N, Multani NK. Influence of age on pulmonary function tests. J Exer Sci Physio 2012; 8:1-6.

29. Hasan H, Arusita R. Perubahan fungsi paru pada usia tua. Jurnal Respirasi 2017;3:52-7. doi: 10.18376/2012/v8i1/67598

30. Kim CH, Wheatley CM, Behnia M, Johnson BD. The effect of aging on relationships between lean body mass and VO2 in rowers. PLoS ONE 2016;11:e0160275. doi:10.1371/journal.pone. 0160275 .

31. Burtscher M. Exercise limitations by the oxygen delivery and utilization systems in aging and disease: coordinated adaptation and deadaptation of the lung-heart muscle axis - a mini-review. Gerontology 2013;59:289-6. doi: 10.1159/ 000343990.

32. Rahmania S.K, Prabowo T, Tessa P. Correlation between forced expiratory volume one second and vital capacity with VO2 maximal. AMJ 2016: 430-3. doi: $10.15850 /$ amj.v3n3.868.

33. Fatemi R, Shakerian S, Ghanbarzade M, Habibi A. The comparison of dynamic volumes of pulmonary function between different levels of maximal oxygen uptake. Int Res J Appl Basic Sci 2012;3:667-74.

34. Doewes M, Kiyatno, Suradi. Kontribusi sistem respirasi terhadap VO2 maks. J Respir Indo 2011; 31:10-3.

35. de Silva CG, Franklin BA, Soares de Arau. Influence of central obesity in estimating maximal oxygen uptake. Clinics 2016;71:629-34. doi: 10.6061/clinics/2016(11)02.

36. Bagley L, Slevin M, Bradburn S, et al. Sex differences in the effects of 12 weeks sprint interval training on body fat mass and the rates of fatty acid oxidation and VO2 max during exercise. BMJ Open Sport Exerc Med 2016;2: e000056. doi:10.1136/bmjsem-2015-000056. 